\title{
Verapamil in the treatment of paroxysmal supraventricular tachycardia
}

\author{
DENNIS M. KRIKLER \\ M.D., F.R.C.P., F.A.C.C. \\ Cardiovascular Division, Royal Postgraduate \\ Medical School, London, W.12
}

\author{
Roworth A. J. SpURrell \\ B.Sc., M.B., M.R.C.P. \\ Department of Cardiology, \\ Guy's Hospital, London, S.E.1
}

\begin{abstract}
Summary
Verapamil is a novel antiarrhythmic agent which appears to act as a calcium-ion antagonist, blocking calcium transport across the myocardial cell membrane. It was given intravenously, in a dose of $10 \mathrm{mg}$, to thirty-two patients suffering from paroxysmal supraventricular tachycardia, and sinus rhythm was achieved promptly in all. Identical results were obtained in a further ten patients with supraventricular tachycardias associated with the Wolff-ParkinsonWhite or other pre-excitation syndromes. In a separate group of eighteen patients in whom A-V junctional tachycardias were induced during intracardiac electrography, conversion to sinus rhythm was achieved in fifteen patients, with prolongation of the cycle length in the others. Circus-movement tachycardias were induced in eight patients with the Wolff-ParkinsonWhite syndrome, and conversion to sinus rhythm was achieved in seven. The results were less consistent in patients with other supraventricular arrhythmias including ectopic atrial tachycardia and atrial flutter, and, in the single patient with supraventricular and ventricular tachycardia, only the former was controlled. In the single patient with atrial fibrillation complicating the Wolff-Parkinson-White syndrome who received verapamil, sinus rhythm was restored. Side effects were few and mild, with rare exceptions of profound hypotension, bradycardia and asystole; their management is discussed, and reasons are advanced why their occurrence is likely to be related either to the concomitant administration of beta-adrenergic blockers or to the presence of sinoatrial disease. It appears that verapamil is particularly suitable for the treatment of supraventricular tachycardias due to a circus movement as calcium antagonism is likely to be most effective in the $\mathbf{N}$ region of the atrioventricular node.
\end{abstract}

VerAPAMIL was originally considered to be a coronary vasodilator (Haas and Härtfelder, 1962), and on this basis was introduced for the treatment of cardiac ischaemia (Tschirdewahn and Klepzig, 1963; Hoffmann, 1964). Under experimental conditions, potent antiarrhythmic activity was noted (Melville, Shister and Huq, 1964; Schmid and Hanna, 1967; Kaumann and Aramendia, 1968) and it is now recog- nized that its antiarrhythmic activity and any action improving cardiac ischaemia is determined by its ability to prevent calcium inflow across the cell membrane (Nayler et al., 1968; Fleckenstein, Döring and Kammermeier, 1968; Nayler and Szeto, 1972; Singh and Vaughan Williams, 1972). In clinical use its antiarrhythmic properties have been demonstrated by Bender et al. (1966) and, in anaesthetized subjects, by Brichard and Zimmerman (1970). Given intravenously, it has been shown to have a potent effect in slowing and regularizing the ventricular response in atrial fibrillation (Schamroth, 1971; Schamroth, Krikler and Garrett, 1972).

In the study reported by Schamroth et al. (1972) twenty patients with paroxysmal supraventricular tachycardia all responded promptly to intravenous verapamil. We have now extended the number of cases treated, and have included a further group in whom paroxysmal supraventricular tachycardias were induced during intracardiac electrographic studies. The response in some other arrhythmias is also briefly considered.

\section{Methods}

Verapamil was administered intravenously as previously described (Schamroth et al., 1972). A dose of $10 \mathrm{mg}$ was given over a period of $15-30 \mathrm{sec}$. In all cases the patients were in the recumbent position, a 12-lead electrocardiogram was first recorded, and the arrhythmia was identified. A continuous electrocardiographic recording was started before the injection and continued until sinus rhythm had been restored, or for at least $5 \mathrm{~min}$. The blood pressure was recorded before, immediately after and on several occasions subsequent to the administration of the verapamil.

In the patients studied in the laboratory, intracardiac electrographic recordings were made and stimulation carried out as previously described (Spurrell, Krikler and Sowton, 1973). Catheters were passed from the femoral veins and positioned in the right atrium, the right ventricle, and across the tricuspid valve in apposition to the bundle of His; in some patients, transseptal puncture was performed and recordings made from the left atrium. In all 


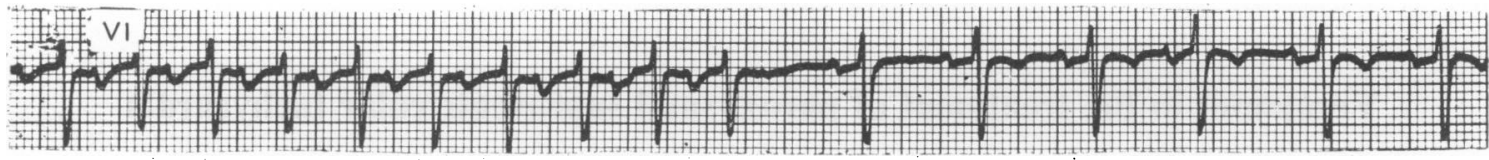

FIG. 1. ECG, showing paroxysmal supraventricular tachycardia at 160 beats a minute, with abrupt conversion to sinus rhythm (100 beats a minute) $40 \mathrm{sec}$ after injection of verapamil.

V2

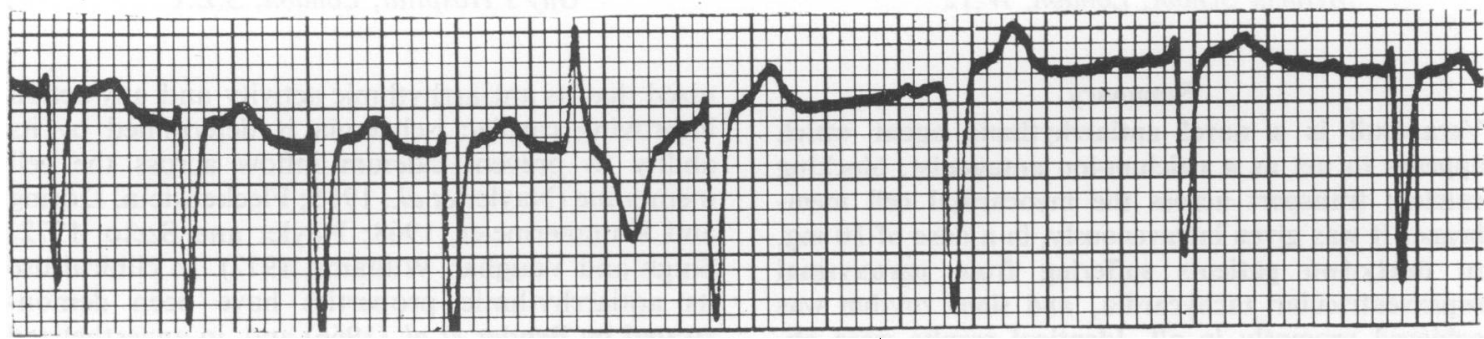

FIG. 2. ECG, showing paroxysmal supraventricular tachycardia with conversion to sinus rhythm 30 sec after verapamil, with ventricular extrasystole at transition.

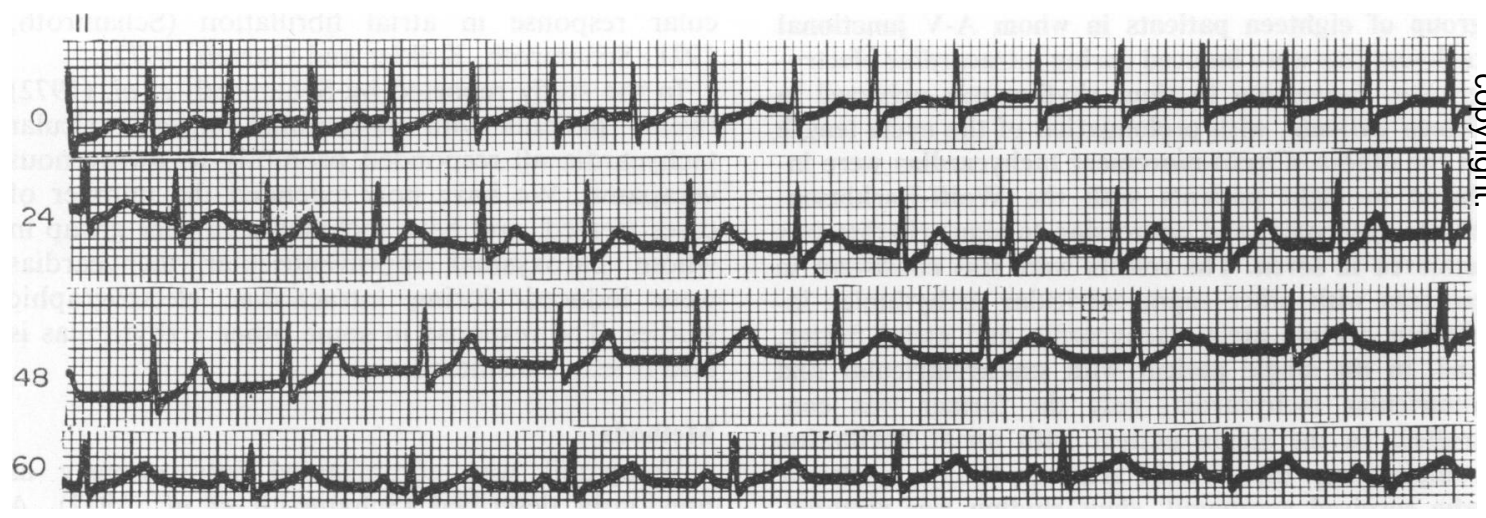

Fig. 3. ECG (lead II) showing paroxysmal supraventricular tachycardia ( 160 beats a minute) in upper panel $(0=$ prior to injection of verapamil). The middle two panels start 24 and $48 \mathrm{sec}$ after verapamil, respectively, and show persistence of tachycardia pattern with progressive slowing of heart rate down to 84 beats a minute. Note the progressive PR lengthening to $0.48 \mathrm{sec}$. In the bottom panel $(60 \mathrm{sec})$ sinus rhythm has been restored at a rate of 78 beats a minute, with a normal PR interval of $0 \cdot 16 \mathrm{sec}$.

patients the procedure was essential to obtain information in the interests of their health; they were fully informed of what was to be done, and consented to the study. Verapamil was administered in the same dose and tracings recorded as appropriate both from intracardiac electrodes and surface leads, and the response to verapamil noted.

\section{Results}

Clinical cases

Thirty-two patients suffered from paroxysmal supraventricular tachycardia due to a circus movement affecting the atrioventricular node, and all responded promptly to the verapamil. Typical responses are shown in Figs. 1 and 2, and consisted either of an abrupt change to sinus rhythm, or one punctuated by the occurrence of one or more ventricular extrasystoles; there was often a brief period of sinus bradycardia, lasting for $30-60 \mathrm{sec}$. There was occasional evidence of antero-grade A-V nodal conduction delay prior to restoration of sinus rhythm, as is demonstrated in Fig. 3, where progressive PR lengthening occurred with persistence of the tachycardia, until abrupt restoration of sinus rhythm with a normal PR interval.

Mild transient hypotension, with a drop in the 

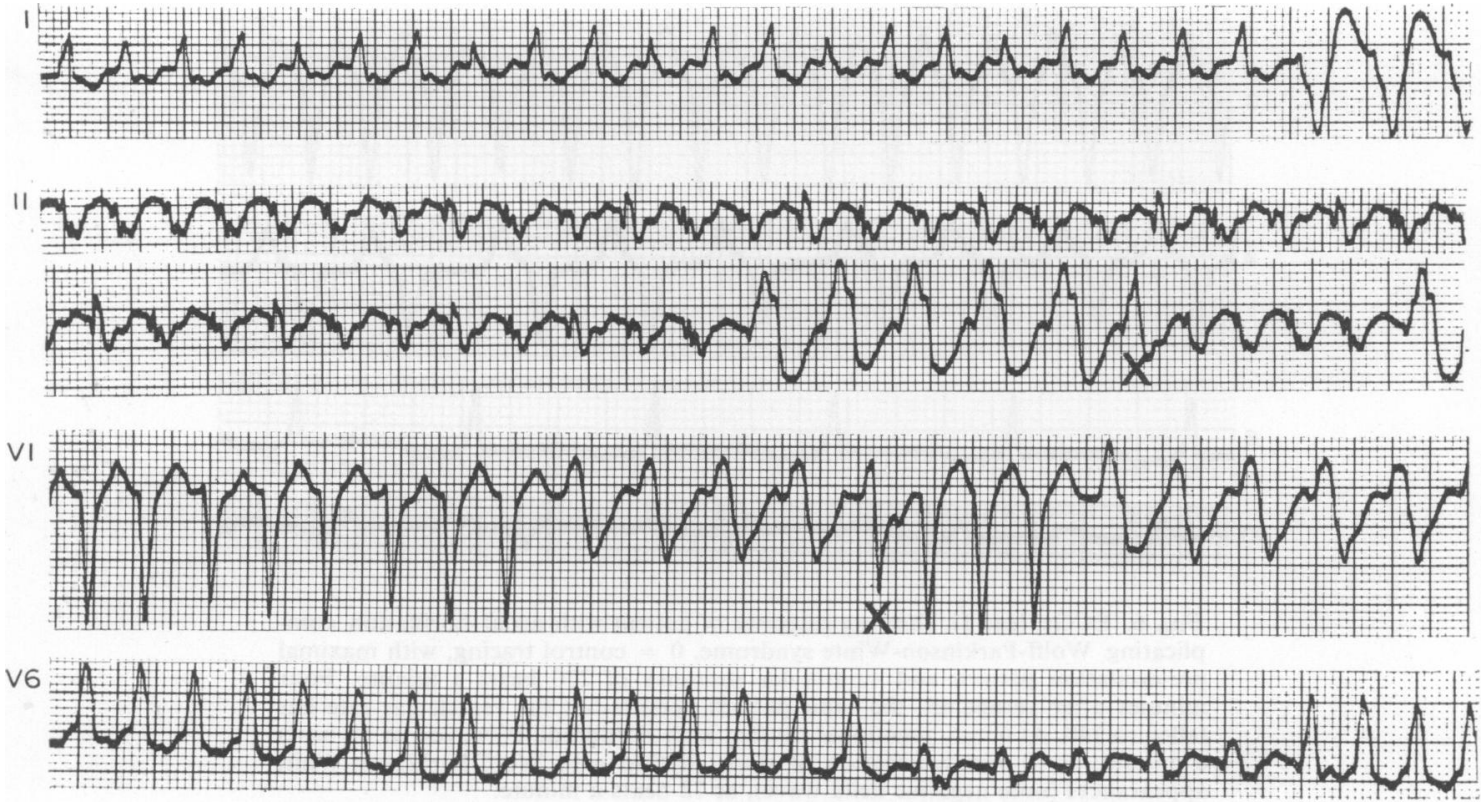

FIG. 4. ECG, showing paroxysmal supraventricular tachycardia (rate 200 beats a minute with alternating intranodal conduction pathways or dissipation of intraventricular conduction disturbance affecting every third beat), with runs of broad complexes due to paroxysmal ventricular tachycardia at 135 beats a minute. Note fusion beats (X) at interface of dual tachycardias.

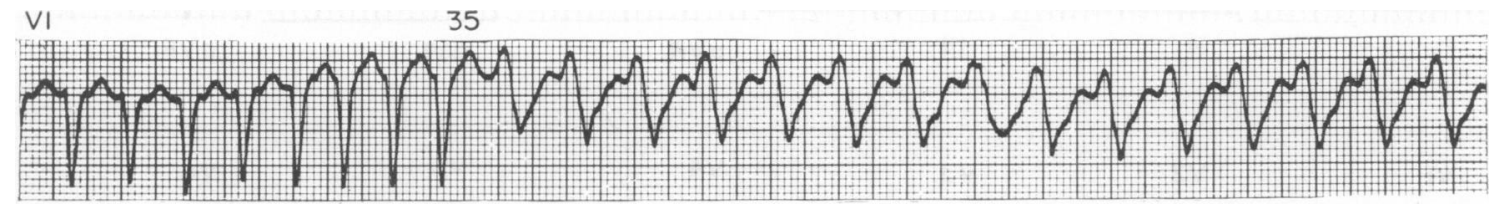

FIG. 5. ECG, lead VI: $35 \mathrm{sec}$ after verapamil, paroxysmal supraventricular tachycardia is completely suppressed, unmasking ventricular tachycardia which persisted until DC cardioversion used.

systolic pressure to $80-100 \mathrm{mmHg}$ for $2-3 \mathrm{~min}$, was noted in four patients, but recovery was spontaneous. However, in a further three patients, more marked hypotension, of the order of $60-40 \mathrm{mmHg}$, was noted, and all these patients were then found to have received oral beta-blocking agents (propranolol or practolol) in normal therapeutic doses on the same day.

Four patients with ectopic atrial tachycardia received verapamil. In one patient, there was conversion to sinus rhythm, preceded by $A-V$ nodal Wenckebach periods (see Fig. 7 in the report by Schamroth et al., 1972). In another patient, in whom the aetiology was congestive cardiomyopathy, the tachycardia was converted to atrial fibrillation which spontaneously changed to sinus rhythm 1 day later; in the other patients, in whom the arrhythmia was believed to be due to thyroxine overdose in one and to cardiac ischaemia in the other, there was a transient increase in the degree of atrioventricular block.
This is similar to our further experience with atrial flutter, which has proved less promising than the original findings (Schamroth et al., 1972). We have administered verapamil to twenty patients, achieving sinus rhythm in five and a transient increase in the degree of atrioventricular block in the remaining fifteen, without altering the cycle length of the flutter waves in any.

A 61-year-old man who suffered from a dual paroxysmal tachycardia of both supraventricular and ventricular origin (Fig. 4), possibly due to digitalis intoxication, responded promptly to intravenous verapamil in that the supraventricular tachycardia was completely controlled, but the ventricular tachycardia persisted (Fig. 5), with consequent haemodynamic deterioration and the need for DC shock.

Ten patients who had reciprocating tachycardias associated with pre-excitation syndromes all responded promptly to intravenous verapamil, with 


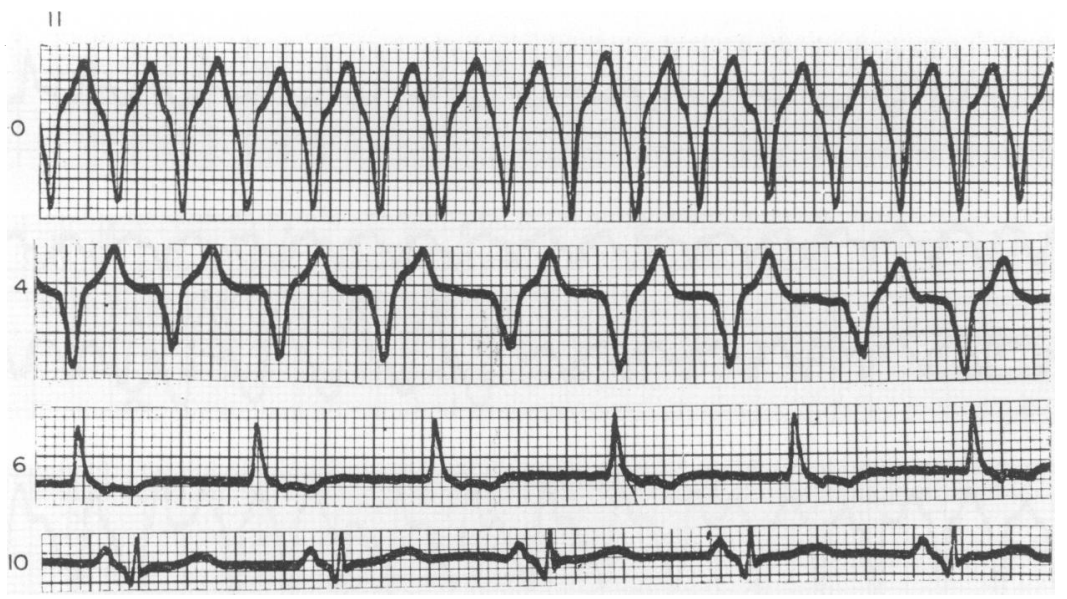

FIG. 6. ECGs, lead II, showing response of patient with atrial fibrillation complicating Wolff-Parkinson-White syndrome. $0=$ control tracing, with maximal pre-excitation pattern and ventricular response of 230 beats a minute. Four minutes after verapamil, the same pattern persists but the ventricular rate has fallen to 140. At $6 \mathrm{~min}$, junctional rhythm with retrograde $P^{\prime}$-waves, at 80 beats a minute; at $10 \mathrm{~min}$, restoration of sinus rhythm with Wolff-Parkinson-White appearances (note negative delta wave), at 72 beats a minute.

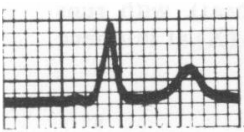

1

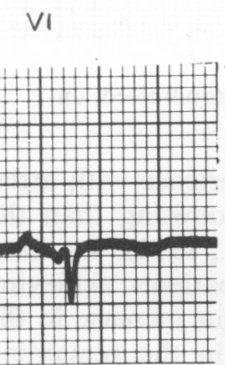

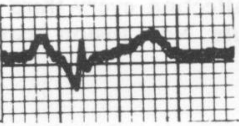

II

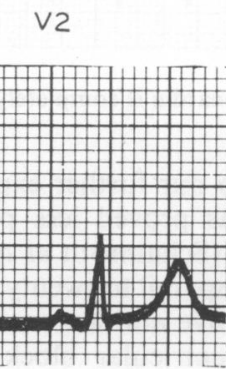

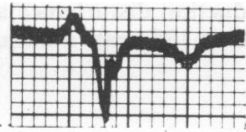

III

V3

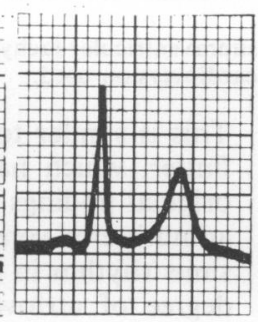

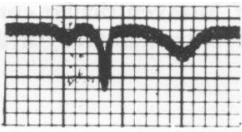

aVR

V4

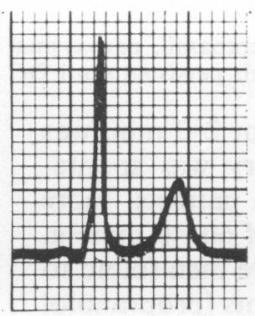

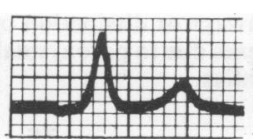

aVL

V5

V6

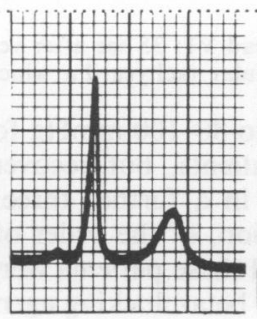

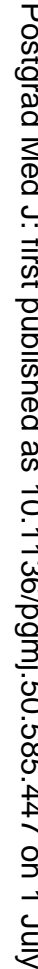

FIG. 7. Wolff-Parkinson-White syndrome, Type B, with negative delta wave and dominant $\mathrm{S}$ in VI.

conversion to sinus rhythm within $2 \mathrm{~min}$. One of these patients, a 68-year-old woman, appears also to have sinoatrial disease as judged by marked sinus bradycardia and sinus arrhythmia and junctional or ventricular escape beats while not receiving antiarrhythmic medications; paroxysmal supraventricular tachycardia occurred despite the prophylactic oral administration of practolol $400 \mathrm{mg}$ daily. She received $10 \mathrm{mg}$ verapamil intravenously, which produced prompt control of the arrhythmia, but with temporary sinus arrest, necessitating temporary ventricular pacing before sinus rhythm was restored.

An additional observation, in a single case of atrial fibrillation complicating the Wolff-ParkinsonWhite syndrome, is instructive. A 36-year-old woman had suffered one previous attack of palpitations, and was admitted with an irregular tachycardia with wide QRS complexes (Fig. 6). This has the appearance of atrial fibrillation complicating the WolffParkinson-White syndrome, most of the impulses being conducted totally down the anomalous tract. The response to intravenous verapamil was at first 
slowing of the ventricular response $(4 \mathrm{~min})$, then development of junctional rhythm with narrow QRS complexes (6 min), and, after $10 \mathrm{~min}$, restoration of sinus rhythm with the pre-excitation pattern (see also Fig. 7).

\section{Intracardiac studies}

Eighteen patients with A-V junctional tachycardias were given verapamil while in circus-movement tachycardia, and in fifteen patients the tachycardia was terminated within 2-3 min. In the remaining three cases, the cycle length was prolonged in both the anterograde and retrograde directions but reciprocation continued. Cessation of tachycardia could take place with interruption of the circuit either in the anterograde pathway (Fig. 8) or in the retrograde pathway (Fig. 9) within the atrioventricular node. Of these fifteen patients-in whom there was no reason to suspect pre-excitation-the presence of a concealed bypass outside the atrioventricular node was suggested in five by constant ventriculoatrial conduction times which were not influenced by verapamil (Spurrell, Krikler and Sowton, 1974a).

Eight patients with Wolff-Parkinson-White syndrome were given verapamil while in circus-movement tachycardia during laboratory studies, and in seven of these patients the tachycardia was termi-
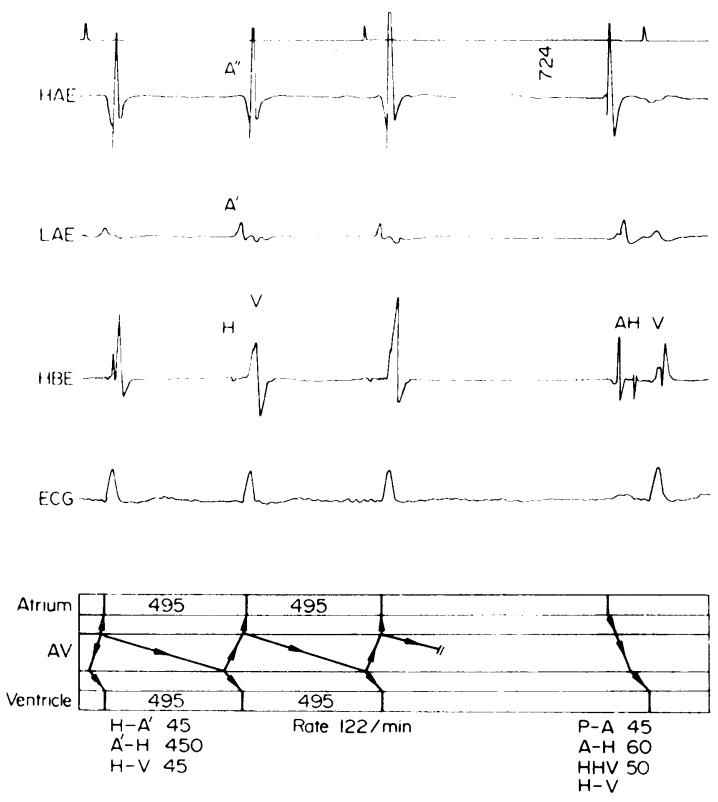

Fig. 8. Intracardiac electrogram showing high right atrial electrogram (HAE), low right atrial electrogram (LAE), His bundle electrogram and simultaneous surface ECG lead. Arrhythmias stopped after third $A^{\prime}$ wave, i.e. in anterograde direction within $\mathrm{A}-\mathrm{V}$ node. The fourth complex shows a sinus beat with normal atrioventricular conduction.
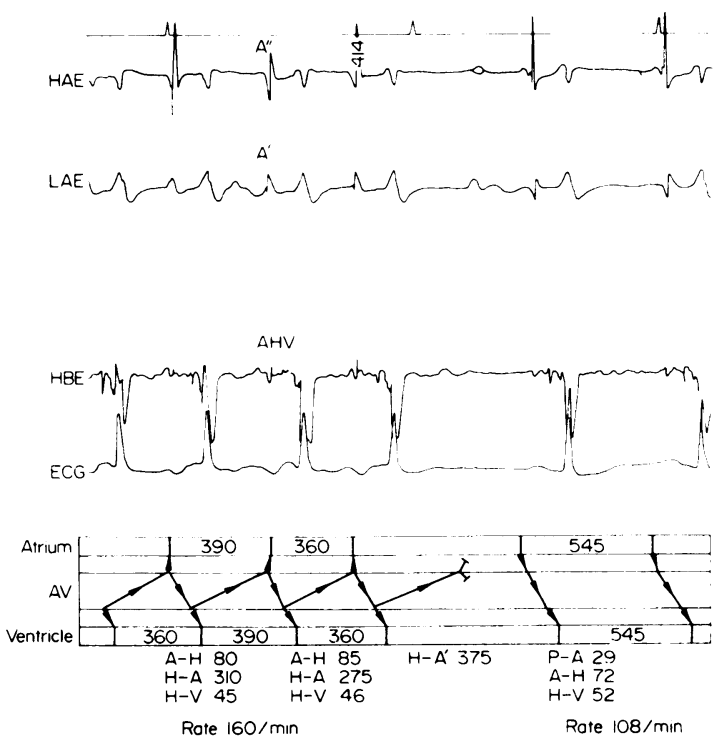

FIG. 9. Intracardiac electrogram, conventions as in Fig. 8. Tachycardia stops after fourth $\mathrm{V}$ wave, i.e. in retrograde conduction within A-V node; the next two complexes are sinus beats with normal atrioventricular conduction.

nated within $2 \mathrm{~min}$. In the remaining patient, a suitably-timed extrasystole was injected in order to disrupt the circuit, as described by Wellens (1971).

\section{Comment}

Whether circus-movement tachycardia is due to a process involving the atrioventricular node alone, or whether the circuit involves an anomalous pathway as well as the A-V node, verapamil appears to be a highly effective antiarrhythmic agent, acting directly on the A-V node. The onset of action is rapid, and the response prompt. Intracardiac studies show that verapamil has a potent effect in prolonging A-V nodal conduction (Puech, 1972a; Husaini et al., 1973; Roy, Spurrell and Sowton, 1974). However, in a certain number of cases, side effects have been noted, including hypotension, bradycardia and on rare occasions, cardiac arrest (Benaim, 1972; Boothby, Garrard and Pickering, 1972; Sacks and Kennelly, 1972). In the majority of such cases, the prior administration of beta-adrenergic blockers appears to have been an important factor. As has been shown by Nayler and Szeto (1972), verapamil and betaadrenergic blockers both have calcium-antagonistic properties on the cell though working in totally different ways. Whereas verapamil blocks transport of calcium across the cell membrane, beta-blockers interfere with intracellular calcium handling. Separately each has a mild negative inotropic effect; when given together, this is additive (Nayler, 1974). 
Another possible mode of adverse reaction to verapamil implies depression of S-A nodal activity. Under normal circumstances, the administration of verapamil has very little if any effect on S-A nodal automaticity (Puech, 1972a; Roy et al., 1974), but if there is sinoatrial disease, it is to be anticipated that any slight inherent tendency to depression will be increased. For this reason verapamil should be used with caution in patients with the 'sick sinus syndrome' who present with supraventricular tachycardia (Husaini et al., 1973), as, indeed, should other drugs. The summation of these effects is well shown in the patient with Wolff-Parkinson-White syndrome and sinoatrial disease in whom transient cardiac standstill was produced after correction of her circusmovement tachycardia.

We have encountered seven other patients in whom there were adverse effects after intravenous verapamil. In four, verapamil had been administered to patients who were already receiving beta-blockers. A 64-year-old patient with the Wolff-ParkinsonWhite syndrome who had received repeated intravenous injections of practolol and propranolol and who had needed DC cardioversions and triple-beat ventricular pacing, suffered from repeated bouts of tachycardia with rates up to 300 a minute, and episodes of ventricular fibrillation, for 4 days: verapamil produced conversion to sinus rhythm but she collapsed with asystole.

While Puech (1972a) has found atropine regularly to reverse the effect of verapamil on the A-V node, others have found the response to be incomplete (Roy et al., 1974). Atropine $1 \mathrm{mg}$ intravenously should, however, be given if a reaction occurs, followed by intravenous calcium $(10-20 \mathrm{ml}$ of $10 \%$ solution); an intravenous infusion of isoprenaline may be needed and, rarely, temporary ventricular pacing. The chance of an adverse reaction can be minimized if it can be ensured that the patient has not been receiving a beta-blocker for at least $6 \mathrm{hr}$ prior to the administration of verapamil. Suspicion of sinoatrial disease merits especial caution in the use of verapamil. However, perspective must be maintained, as adverse reactions occur to other antiarrhythmic agents, e.g. beta-adrenergic blockers (Szekely, 1972), and G. C. Sutton (personal communication) has observed hypotension and pulmonary oedema in a patient with paroxysmal supraventricular tachycardia treated with intravenous practolol who failed to return to sinus rhythm. Furthermore, ill patients who have suffered from arrhythmias for a protracted period are likely to have catecholamine depletion, and may well react adversely both to betaadrenergic blockers and to verapamil, or indeed any substance that decreases the amount of calcium entering or available within the myocardial cell.

The response in atrial fibrillation complicating the
Wolff-Parkinson-White syndrome (Fig. 8) was positive but difficult to understand unless it can be inferred that the initial decrease in ventricular rate was due to a blocking action at the atrio-bypass junction and a subsequent antifibrillatory effect on the atrium, restoring sinus rhythm via a phase of junctional rhythm. Verapamil does not lengthen the refractory period of the bypass, tending not to influence it or to produce slight shortening (Spurrell et al., 1974b).

In the vast majority of published reports, results of treatment have been excellent (Abaza et al., 1972; Gotsman et al., 1972; Filias and Zanoni, 1972; Puech, 1972b). Verapamil has been shown to have an important place in the treatment of paroxysmal A-V nodal tachycardia. Our experience has been confined to its intravenous use and we have not made any systematic assessment of its efficacy when given by mouth for treatment or prophylaxis, though others have reported satisfactory results (Bender, 1970; Abaza et al., 1972; Filias and Zanoni, 1972; Puech, 1972b). Its preferential action on the A-V node may be due to the fact that its potent calcium antagonism is most sensitively felt in the $\mathbf{N}$ region of the node, where a slow $\mathrm{Na}^{+}-\mathrm{Ca}^{++}$channel determines conduction (Zipes, 1973). Provided precautions are taken in the selection of patients and in the exclusion of those who have recently received beta? adrenergic blockers, use of verapamil in supraventri cular tachycardias provides an important and usefue form of therapy. Whether the mechanism involves the A-V node alone or the A-V node plus an extranodal bypass, verapamil has been shown to be a safe and effective primary agent for the treatment of circus-movement supraventricular tachycardias.

\section{References}

Abaza, A., Bodinier, C., Aziza, Cl. \& Garnier, J.C. (1972) Étude clinique d'un nouvel antiarythmique. Coeur et Médecine Interne, 11, 757.

BenAim, M.E. (1972) Asystole after verapamil. British Medical Journal, 2, 169.

BENDER, F. (1970) Die Behandlung der tachycarden Arrhythmien und der arteriellen Hypertonie mit Verapamil. Arzneimittel-Forschung, 20, 1310.

Bender, F., Kojima, N., Reploh, H.D. \& Oelmann, G. (1966) Behandlung von Rhythmusstörungen des Herzens durch Beta-Rezeptorenblockade des Atrioventrikulargewebes. Medizinische Welt, 17, 1120.

Brichard, G. \& ZimmermanN, P.E. (1970) Verapamil in cardiac dysrhythmias during anaesthesia. British Journal of Anaesthesia, 42, 1005.

Boothby, C.B., Garrard, C.S. \& Pickering, D. (1972) Intravenous verapamil in cardiac arrhythmias. British Medical Journal, 2, 349.

Filias, N. \& ZaNONI, G. (1972) Klinische Analyse der antiarrhythmischen Wirkung des Verapamils. Schweizerischer Medizinische Wochenschrift, 102, 406.

Fleckenstein, A., Döring, H.J. \& Kammermeier, H. (1968) Einfluss von Beta-Receptorenblockern und verwandten Substanzen auf Erregung, Kontraktion und Energiestoffwechsel der Myokardfaser. Klinische Wochenschrift, 46, 343. 
Gotsman, M.S., Lewis, B.S., Bakst, A. \& Mitha, A.S. (1972) Verapamil in life-threatening tachyarrhythmias. South African Medical Journal, 46, 2017.

HAAS, H. \& HÄRTFELDER, G. (1962) $\alpha$-Isopropyl- $\alpha-[(N-$ methyl - N - homoveratryl) - $\gamma$ - amino - propyl] - 3,4 - dimethoxyphenylacetonitril, eine Substanz mit koronargefässerweiternden Eigenschaften. Arzneimittel-Forschung, $12,549$.

HoffmanN, P. (1964) Behandlung koronarer Durchblutungsstörungen mit Isoptin in der Praxis. Medizinische Klinik, 59, 1387.

Husaini, M.H., Kvasnicka, J., Rydén, L. \& Holmberg, S. (1973) Action of verapamil in sinus node, atrioventricular, and intraventricular conduction. British Heart Journal, 35, 734.

Kaumann, A.J. \& Aramendia, P. (1968) Prevention of ventricular fibrillation induced by coronary ligation. Journal of Pharmacology and Experimental Therapeutics, 164, 326.

Melville, K.I., Shister, H.E. \& HuQ, S. (1964) Iproveratril: Experimental data on coronary dilation and antiarrhythmic action. Canadian Medical Association Journal, 90, 761.

NAYLER, W.G. (1974) The sub-cellular regulation of myocardial function. American Heart Journal. (In press.)

Nayler, W.G., McInnes, I., Swann, J.B., Price, J.M., Carson, V., Race, D. \& Lowe, T.E. (1968) Some effects of iproveratril (isoptin) on the cardiovascular system. Journal of Pharmacology and Experimental Therapeutics, $161,247$.

NAYLeR, W.G. \& Szeto, J. (1972) Effect of verapamil on contractibility, oxygen utilization, and calcium exchangeability on mammalian heart muscle. Cardiovascular Research, 6, 120.

Puech, P. (1972a) Dissection de la Conduction Sinoventriculaire pour l'Étude du Vérapamil Injectable (circulated privately).

PuECH, P. (1972b) Expérimentation Clinique de l'Isoptine Injectable et par Voie Orale dans les Troubles du Rythme Cardiaque (circulated privately).

Roy, P.R., Spurrell, R.A.J. \& Sowton, E. (1974) The effect of verapamil on the conduction system in man. Postgraduate Medical Journal, 50, 270.

SaCKS, H. \& KenNelly, B.M. (1972) Verapamil in cardiac arrhythmias. British Medical Journal, 2, 716.
Schamroth, L. (1971) Immediate effects of intravenous verapamil on atrial fibrillation. Cardiovascular Research, 5, 419.

Schamroth, L., Krikler, D.M. \& GarretT, C. (1972) Immediate effects of intravenous verapamil in cardiac arrhythmias. British Medical Journal, 1, 660.

Schmid, J.R. \& HaNNA, C. (1967) A comparison of the antiarrhythmic actions of two new synthetic compounds, iproveratril and MJ 1999, with quinidine and pronethalol. Journal of Parmacology and Experimental Therapeutics, 156, 331.

Singh, B.N. \& Vaughan Williams, E.M. (1972) A fourth class of anti-dysrhythmic action? Effect of verapamil on ouabain toxicity, on atrial and ventricular intracellular potentials, and on other features of cardiac function. Cardiovascular Research, 6, 109.

Spurrell, R.A.J., Krikler, D.M. \& Sowton, E. (1973) Two or more intra AV nodal pathways in association with either a James or Kent extranodal bypass in 3 patients with paroxysmal supraventricular tachycardia. British Heart Journal, 35, 113.

Spurrell, R.A.J., Krikler, D.M. \& Sowton, E. (1974a) Concealed bypass of the AV node in patients with paroxysmal supraventricular tachycardia revealed by intracardiac electrical stimulation and intravenous verapamil. American Journal of Cardiology (in press).

Spurrell, R.A.J., Krikler, D.M. \& Sowton, E. (1974b) The effects of verapamil on the electrophysiological properties of the anomalous atrioventricular connexions in Wolff-Parkinson-White syndrome. British Heart Journal, 36, 256.

Szekely, P. (1972) In: Proceedings of United KingdomScandinavian Cardiology Meeting (Ed. by J. L. Kennedy). Watford, Astra Chemicals Limited.

TschirdewaHN, B. \& KLEP7.IG, H. (1963) Klinische Untersuchung über die Wirkung von Isoptin und Isoptin $\mathbf{S}$ bei Patienten mit Koronarinsuffizienz. Deutsche Medizinische Wochenschrift, 88, 1702.

WELlENS, H.J.J. (1971) Electric Stimulation of the Heart in the Study and Treatment of Tachycardias. (Ed. by H. E. Stenfert Kroese, N.V.). Leiden.

ZIPES, D.P. (1973) In: Cardiac Arrhythmias (Ed. by L. S. Dreifus and W. Likoff), p. 55. New York, Grune and Stratton. 